\title{
Exploring the emergence of an 'Aquatic' Neolithic in the Russian Far East: organic residue analysis of early hunter- gatherer pottery from Sakhalin Island
}

Kevin Gibbs ${ }^{1}$, Sven Isaksson ${ }^{2}$, Oliver E. Craig ${ }^{3}$, Alexandre Lucquin ${ }^{3}$, Vyacheslav A. Grishchenko ${ }^{4}$, Tom F.G. Farrell ${ }^{3,5}$, Anu Thompson ${ }^{6}$, Hirofumi Kato ${ }^{7}$, Alexander A. Vasilevski ${ }^{8} \&$ Peter D. Jordan ${ }^{5, *}$

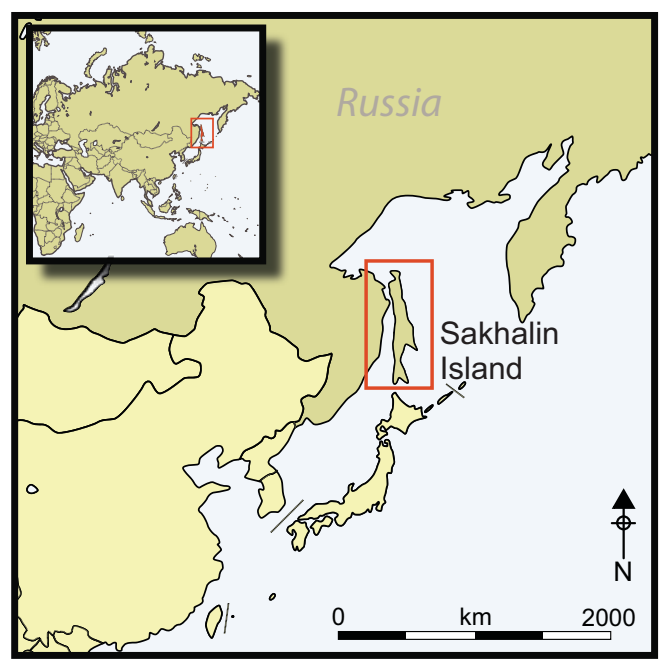

The Neolithic in north-east Asia is defined by the presence of ceramic containers, rather than agriculture, among huntergatherer communities. The role of pottery in such groups has, however, hitherto been unclear. This article presents the results of organic residue analysis of Neolithic pottery from Sakhalin Island in the Russian Far East. Results indicate that early pottery on Sakhalin was used for the processing of aquatic species, and that its adoption formed part of a wider Neolithic transition involving the reorientation of local lifeways towards the exploitation of marine resources.

Keywords: Sakhalin Island, Neolithic, organic residues, hunter-gatherers, aquatic resources

1 Archaeological Research Facility, University of California, Berkeley, 2251 College Avenue, Berkeley, CA 947201076, USA

2 Archaeological Research Laboratory, Department of Archaeology and Classical Studies, Stockholm University, SE10691 Stockholm, Sweden

3 BioArCh, Department of Archaeology, University of York, Heslington, York YO10 5DD, UK

4 Educational Archaeological Museum, Sakhalin State University, Lenin Street 290, Yuzhno-Sakhalinsk 693000, Russia

5 Arctic Centre \& Groningen Institute of Archaeology, Aweg 30, 9718 CW, Groningen, the Netherlands

6 School of Environmental Sciences, Nicholson Building, 4 Brownlow Street, University of Liverpool, Liverpool L69 3GP, UK

Center for Ainu \& Indigenous Studies, Hokkaido University, Kita 8, Nishi 6, Kita-ku, Sapporo 060-0808, Japan

8 Sakhalin Joint Laboratory of the Institute of Archaeology and Ethnography of the Siberian Branch of the Russian Academy of Science and the Sakhalin State University, Lenin Street 290, Yuzhno-Sakhalinsk 693008, Russia

* Author for correspondence (Email: p.d.jordan@rug.nl)

(C) Antiquity Publications Ltd, 2017

ANTIQUITY 91360 (2017): 1484-1500 


\section{Introduction}

The Neolithic was marked by major shifts in economy, technology and settlement, making it one of the most important periods of development in human prehistory (Uchiyama et al. 2014: 197). Archaeologists working across Eurasia are now highlighting two contrasting Neolithic 'trajectories' (Gibbs \& Jordan 2016). The classic 'Western' Neolithic witnessed the emergence of farming economies in the Near East and their dispersal into northwest Europe, along with a package of other innovations including pottery, ground-stone tools and village life. In contrast, the 'Eastern' Neolithic trajectory is associated with the emergence of pottery among foraging societies. Importantly, this early use of pottery began long before and independently of any transition to farming.

The Eastern Neolithic trajectory developed slowly across an extended Eurasian transect: it emerged first in Late Pleistocene China, Japan, the Russian Far East and eastern Siberia; during the Holocene, it also appeared in western Siberia, the Urals and European Russia, and somewhat later in the eastern Baltic and Arctic Norway (Jordan \& Zvelebil 2009; Gibbs \& Jordan 2013; Jordan et al. 2016). Understanding what factors drove the appearance of pottery is of central importance, as it marks the onset of the Eastern Neolithic. The precise role of pottery within local hunter-gatherer lifeways has, however, remained uncertain.

Biomolecular analysis of the organic residues preserved on pottery surfaces and within the clay matrix now provides one of the most direct methods for reconstructing vessel function (Evershed 2008). Recent research has focused on the analysis of early pottery from Japan, one of the oldest centres of ceramic innovation (Craig et al. 2013; Luquin et al. 2016). More work, however, is needed in adjacent areas to understand the factors that encouraged the wider uptake of early pottery traditions in surrounding regions. This article addresses that issue, and aims to understand how and why knowledge of pottery technology was able to spread northwards, out of the Japanese archipelago, and onto Sakhalin Island in the Russian Far East (Figure 1). The results of organic residue analysis indicate that the early pottery on Sakhalin was used in the processing of aquatic species, and that its adoption was central to the Neolithic transition in this area, which involved a wider reorientation of local lifeways towards the exploitation of marine resources.

\section{The Neolithic of Sakhalin Island}

The onset of Holocene warming created major environmental challenges for the Palaeolithic hunter-gatherer communities who had colonised Sakhalin by around 20000 cal BP (Vasilevski 1994, 2003, 2008; Kuzmin et al. 2004). After a long transitional period, the emergence of pottery marks the onset of the Early Neolithic on Sakhalin at around 9000 7200 years ago. This was followed by the Middle and Late Neolithic phases, which date to approximately 7200-2500 years ago (Vasilevski \& Shubina 2006: 154; Zhushchikhovskaya 2009; Vasilevski et al. 2010). Throughout the Neolithic, Sakhalin had a temperate climate and was mainly covered by coniferous forest, with deciduous forest in some western areas (Aleksandrova 1982; Mikishin \& Gvozdeva 1996; Vasilevski 1998; Vasilevski \& Shubina 2002; Kuzmin 2006a; Rudaya et al. 2013). 


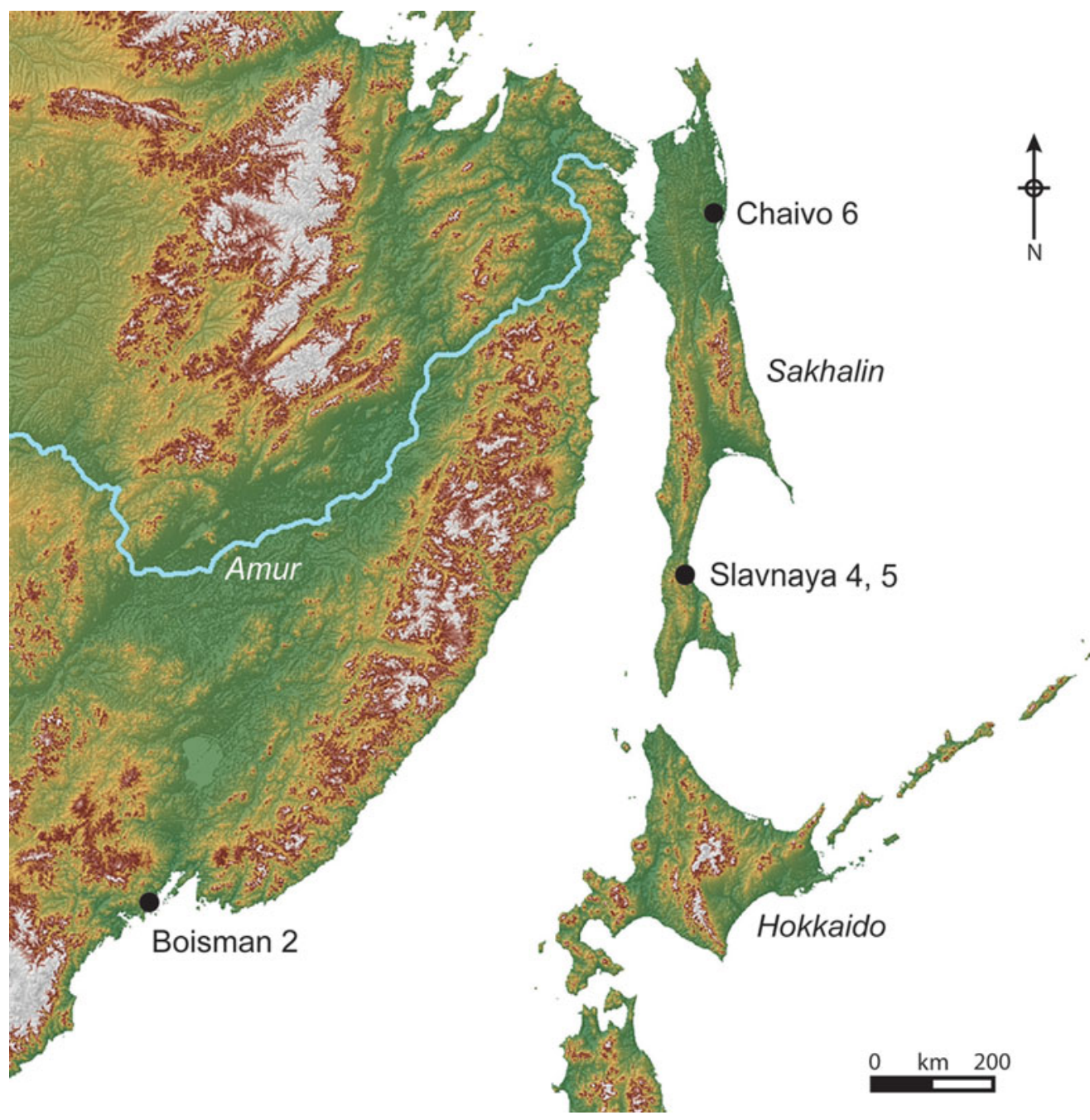

Figure 1. Sakhalin Island and adjacent regions, showing sites mentioned in the text.

The precise function of early pottery on Sakhalin remains unclear despite its vital importance in defining the Neolithic. One persistent problem is the acidic soils found across Sakhalin and the Russian Far East; only a handful of archaeological sites, such as caves or shell middens, have produced faunal or botanical assemblages (e.g. Vostretsov 1998; Popov et al. 2014). Despite these challenges, available data on prehistoric economic patterns have been summarised across north-east Asia in terms of broad economic-cultural types (see: Kuzmin 2005: 185-87, 2006b: 172). In this view, during the Early Neolithic, it is thought that Sakhalin was occupied by hunter-fisher-gatherer cultures who inhabited the forested ecosystems (including at the locations of Slavnaya 4, Slavnaya 5 and Chaivo 6; see below); coastal hunters exploiting marine mammals are recorded only in the extreme southern tip. By the Late Neolithic, hunter-fisher-gatherers were occupying the forest ecosystems across

(C) Antiquity Publications Ltd, 2017 
the entire island, but the extent to which they were exploiting coastal resources remains unclear (Kuzmin 2005: 188, fig. 45).

Recent infrastructure development on Sakhalin has resulted in an increased number of rescue excavations. Local archaeologists are now synthesising the new data and are starting to frame the Neolithic transition in Sakhalin in terms of a broader behavioural response to environmental changes that were triggered by the onset of Holocene warming. It has been suggested that the growing importance of aquatic species was the main driving force of the transition process and culminated in a new way of life that focused on coastal and riverine settings, and which involved the exploitation of maritime bio-resources (Vasilevski 2008; Grishchenko 2011). Three lines of evidence are used to support this interpretation: a) changing settlement and demography - Neolithic sites cluster along coastlines and along the lower reaches of large rivers; an increasing number of sites suggest higher population density, and the appearance of pit houses suggests growing sedentism; b) innovations in technology — tool kits include fishing equipment, such as polished rods and notched stone fishing weights (e.g. Figures $2.10 \& 3.8$ ), and a new range of wood-working implements (e.g. axes, adzes, chisels) that may have been used for building large permanent structures or water craft; c) maritime exchange networks-Neolithic sites across Sakhalin frequently contain obsidian, which probably originated in Hokkaido (Kuzmin \& Glascock 2007).

The adoption of pottery technology into Sakhalin is thought to represent one further element in this wider adjustment process and, of course, defines the onset of the Neolithic (Vasilevski 2008; Grishchenko 2011). The oldest pottery on Sakhalin is later in date than in Hokkaido and along the Amur River (Figure 1), and its arrival coincides with warmer conditions. Some pottery-making traditions may have been brought to southern Sakhalin by migrations out of Hokkaido. This may explain the typological similarities in local pottery wares, whereas shell-tempered pottery from northern Sakhalin may ultimately trace its origin back to the Lower Amur River (Zhushchikhovskaya 2009: 137; Vasilevski et al. 2010: 19-20). Either way, the local motivations for the adoption of pottery onto Sakhalin remain unclear. Organic residue analysis offers scope for testing this 'aquatic' Neolithic transition model by directly reconstructing the function of the earliest ceramic vessels found on Sakhalin.

\section{Neolithic sites and samples}

Early pottery from Sakhalin is characterised by small, low-fired, flat-bottomed vessels, probably reflecting limited functional differentiation (Vasilevski \& Shubina 2006: 156; Zhushchikhovskaya \& Shubina 2006; Zhushchikhovskaya 2009: 137). To assess spatiotemporal variation in early pottery function, we selected sites from different parts of the island and sampled sherds from both Early and Middle Neolithic phases.

\section{Slavnaya 4}

Slavnaya 4 is located on southern Sakhalin, on a terrace $400 \mathrm{~m}$ from the coast of the Okhotsk Sea. The site has three occupation phases: an Early Neolithic one followed by two Middle Neolithic phases (Figures $2 \& 3$ ). Excavations in the Early Neolithic deposits recovered evidence for two pit houses, along with 105 pottery sherds derived from flat-bottomed 
Kevin Gibbs et al.
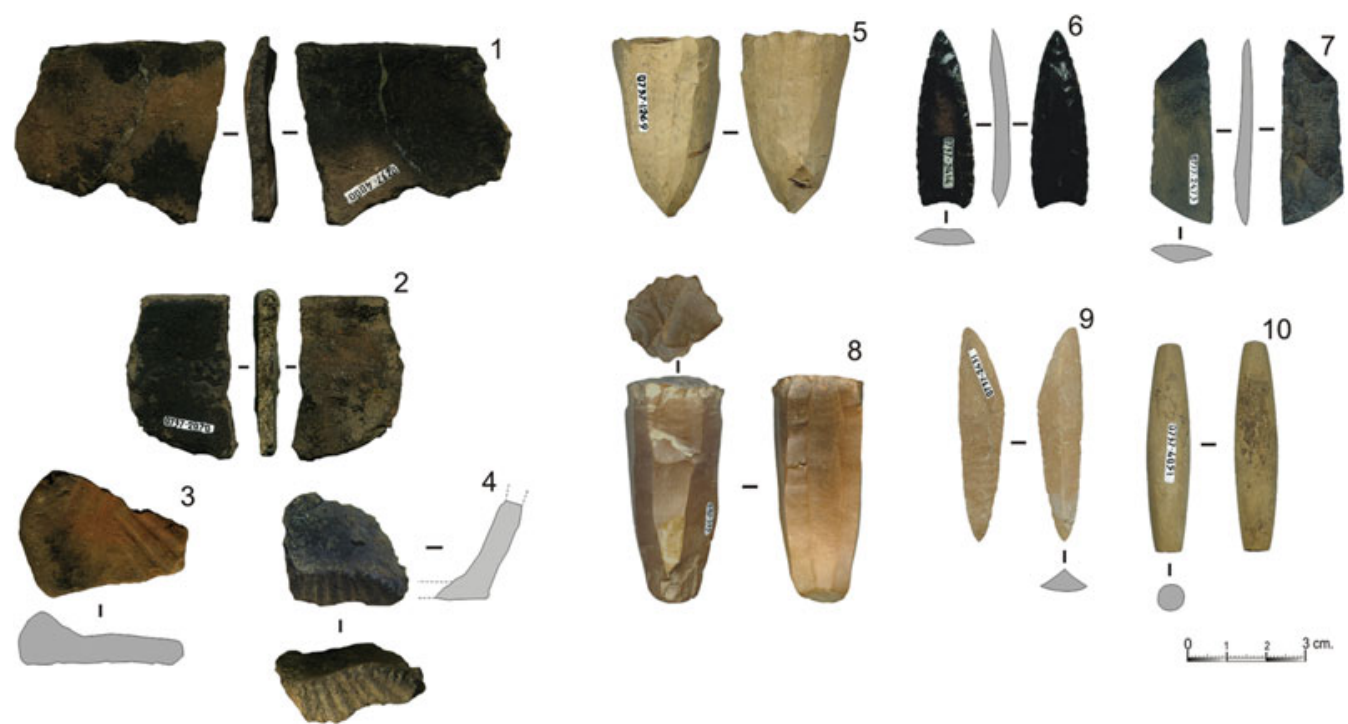

Figure 2. Early Neolithic artefacts from Slavnaya 4: Akatsuki-type pottery (1-4), stone cores (5 \& 8) and tools (6-7 \& 9-10).
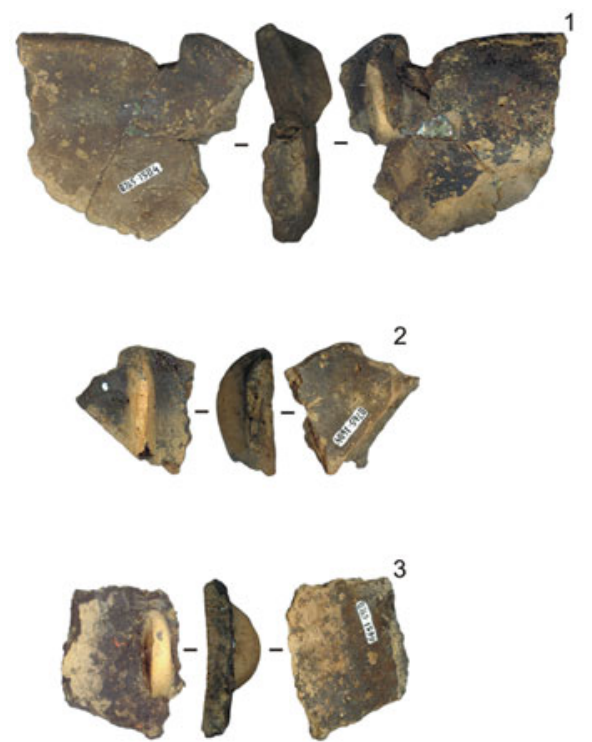
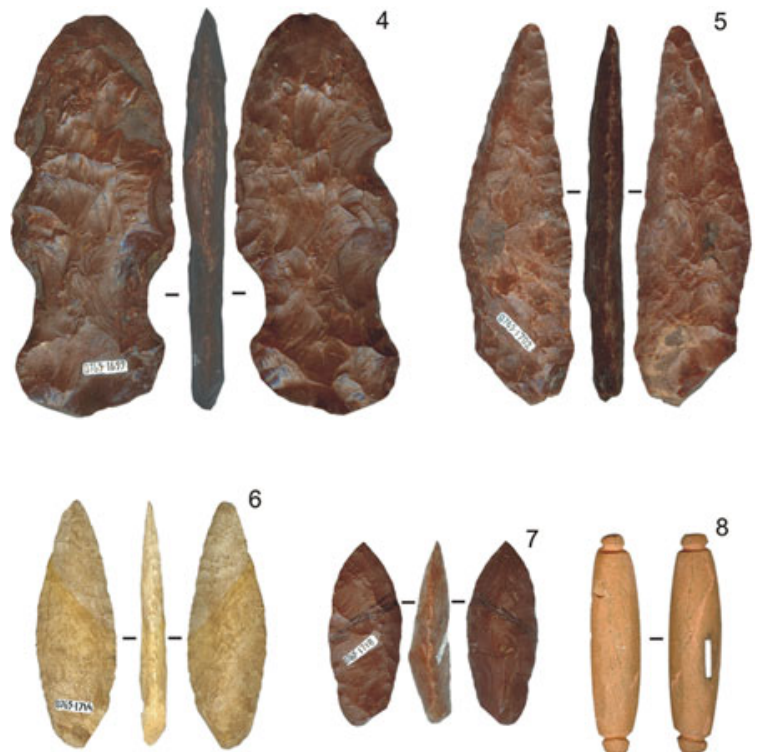

$2 \cdot 2^{30 m}$

Figure 3. Middle Neolithic artefacts from Slavnaya 4: Sony-type pottery (1-3) and stone tools (4-8).

vessels with walls approximately $6-7 \mathrm{~mm}$ thick, and with a slightly concave rim. The pottery is mineral-tempered and exhibits low porosity. Radiocarbon dating of food crusts indicates that this pottery is the oldest yet known on Sakhalin (7300-7050 cal BC; see Table 1). The assemblage includes Akatsuki-type pots, which have a characteristic shell-impression on the (C) Antiquity Publications Ltd, 2017 
Table 1. Radiocarbon dates from Slavnaya 4, Slavnaya 5 and Chaivo 6; calibrated with OxCal v4.3 and IntCal13 (Bronk Ramsey 2009; Reimer et al. 2013).

\begin{tabular}{|c|c|c|c|c|c|c|}
\hline Site & $\begin{array}{l}\text { Cultural } \\
\text { period* }\end{array}$ & $\begin{array}{l}\text { Laboratory } \\
\text { number }\end{array}$ & $\begin{array}{l}\text { Uncalibrated } \\
\text { age BP }\end{array}$ & $\begin{array}{c}\text { Calibrated age } \\
\text { range } \mathrm{BC} \\
(95.4 \% \\
\text { probability })\end{array}$ & Material & Reference \\
\hline Slavnaya 4 & EN & AA-79416 & $8135 \pm 50$ & 7310-7050 & pottery crust & Vasilevski et al. 2010 \\
\hline Slavnaya 4 & EN & AA-79417 & $150 \pm 50$ & 7310-7060 & pottery crust & Vasilevski et al. 2010 \\
\hline Slavnaya 4 & EN & MTC-16741 & $7660 \pm 50$ & $6600-6430$ & pottery crust & Fukuda et al. 2015 \\
\hline Slavnaya 4 & $\mathrm{EN}$ & MTC-16742 & $8410 \pm 50$ & $\begin{array}{l}7580-7420 \\
7420-7360\end{array}$ & pottery crust & Fukuda et al. 2015 \\
\hline Slavnaya 4 & EN & MTC-16743 & $8270 \pm 50$ & 7480-7140 & pottery crust & Fukuda et al. 2015 \\
\hline Slavnaya 4 & EN & MTC-16744 & $8370 \pm 50$ & $7550-7320$ & pottery crust & Fukuda et al. 2015 \\
\hline Slavnaya 4 & EN & MTC-16745 & $8500 \pm 50$ & $7600-7490$ & pottery crust & Fukuda et al. 2015 \\
\hline Slavnaya 4 & EN & MTC-16746 & $8450 \pm 50$ & $\begin{array}{l}7590-7450 \\
7400-7380\end{array}$ & pottery crust & Fukuda et al. 2015 \\
\hline Slavnaya 4 & EN & MTC-16747 & $8170 \pm 50$ & $7320-7060$ & pottery crust & Fukuda et al. 2015 \\
\hline Slavnaya 4 & $\mathrm{EN}$ & MTC-16748 & $8260 \pm 70$ & $\begin{array}{l}7480-7120 \\
7120-7080\end{array}$ & pottery crust & Fukuda et al. 2015 \\
\hline Slavnaya 4 & EN & MTC-16749 & $7920 \pm 70$ & $7040-6650$ & pottery crust & Fukuda et al. 2015 \\
\hline Slavnaya 5 & EN & Beta-32 & $7750 \pm 40$ & $6650-6480$ & pottery crust & this study \\
\hline Slavnaya 5 & EN & MTC-16740 & $7340 \pm 50$ & $\begin{array}{l}6360-6290 \\
6270-6070\end{array}$ & pottery crust & Fukuda et al. 2015 \\
\hline Slavnaya 5 & EN & MTC-16739 & $7825 \pm 50$ & $6830-6510$ & pottery crust & Fukuda et al. 2015 \\
\hline Slavnaya 5 & $\mathrm{EN}$ & MTC-17295 & $7180 \pm 60$ & $\begin{array}{l}6210-5980 \\
5940-5930\end{array}$ & charcoal & Fukuda et al. 2015 \\
\hline Slavnaya 5 & EN & MTC-17296 & $7340 \pm 70$ & $6380-6060$ & charco & Fuk \\
\hline Slavnaya 5 & EN & MTC-17297 & 712 & $6070-5900$ & charc & Fukuda et al. 2015 \\
\hline Slavnaya 5 & $\mathrm{EN}$ & MTC-17298 & $8770 \pm 60$ & $\begin{array}{l}8180-8110 \\
8090-8080 \\
8060-8040 \\
8000-7610\end{array}$ & charcoal & Fukuda et al. 2015 \\
\hline Slavnaya 5 & $\mathrm{EN}$ & MTC-17023 & $7870 \pm 60$ & $\begin{array}{l}7030-6930 \\
6920-6880 \\
6860-6600\end{array}$ & charcoal & Fukuda et al. 2015 \\
\hline Slavnaya 5 & EN & MTC-17024 & $7350 \pm 45$ & $\begin{array}{l}6360-6290 \\
6270-6080\end{array}$ & charcoal & Fukuda et al. 2015 \\
\hline Slavnaya 5 & EN & MTC-17025 & $7290 \pm 50$ & $6240-6050$ & charcoal & Fukuda et al. 2015 \\
\hline Slavnaya 5 & $\mathrm{EN}$ & MTC-17026 & $7430 \pm 80$ & $\begin{array}{l}6440-6200 \\
6190-6100\end{array}$ & charcoal & Fukuda et al. 2015 \\
\hline Slavnaya 5 & EN & MTC-17120 & $7110 \pm 60$ & $\begin{array}{l}6080-5870 \\
5860-5850\end{array}$ & pottery crust & Fukuda et al. 2015 \\
\hline Slavnaya 5 & $\mathrm{EN}$ & MTC-17121 & $7040 \pm 50$ & $6020-5810$ & pottery crust & Fukuda et al. 2015 \\
\hline Slavnaya 5 & $\mathrm{EN}$ & MTC-17122 & & $6230-6020$ & pottery crust & Fukuda et al. 2015 \\
\hline Slavnaya 4 & $\mathrm{MN}$ & MTC-16869 & $6945 \pm 45$ & $\begin{array}{l}5970-5950 \\
5910-5730\end{array}$ & pottery crust & Fukuda et al. 2015 \\
\hline Slavnaya 4 & $\mathrm{MN}$ & MTC-16868 & $7245 \pm 45$ & $6220-6030$ & pottery crust & Fukuda et al. 2015 \\
\hline & $\mathrm{MN}$ & MTC-16867 & & $5670-5490$ & pottery crust & Fukuda et al. 2015 \\
\hline Slavnaya 4 & $\mathrm{MN}$ & MTC-16866 & $6855 \pm 50$ & $5840-5640$ & pottery crust & Fukuda et al. 2015 \\
\hline
\end{tabular}

${ }^{*}$ Key: EN = Early Neolithic; MN = Middle Neolithic. 
Table 1. Continued.

\begin{tabular}{|c|c|c|c|c|c|c|}
\hline Site & $\begin{array}{l}\text { Cultural } \\
\text { period }^{*}\end{array}$ & $\begin{array}{l}\text { Laboratory } \\
\text { number }\end{array}$ & $\begin{array}{c}\text { Uncalibrated } \\
\text { age BP }\end{array}$ & $\begin{array}{l}\text { Calibrated age } \\
\text { range BC } \\
(95.4 \% \\
\text { probability })\end{array}$ & Material & Reference \\
\hline \multirow[t]{2}{*}{ Slavnaya 4} & $\mathrm{MN}$ & SOAN-6685 & $6350 \pm 140$ & $5610-5590$ & $\begin{array}{l}\text { charcoal } \\
\text { from hearth }\end{array}$ & Vasilevski et al. 2010 \\
\hline & & & & $5570-4990$ & & \\
\hline Slavnaya 4 & $\mathrm{MN}$ & AA-79418 & $6670 \pm 45$ & $5670-5510$ & pottery crust & Vasilevski et al. 2010 \\
\hline Chaivo 6 & $\mathrm{MN}$ & SOAN-6094 & $6895 \pm 100$ & $5980-5630$ & charcoal & Vasilevski et al. 2010 \\
\hline Chaivo 6 & MN & SOAN-6095 & $6945 \pm 90$ & $6000-5670$ & charcoal & Vasilevski et al. 2010 \\
\hline
\end{tabular}

${ }^{*}$ Key: EN = Early Neolithic; MN = Middle Neolithic.

flat base, and form an Initial Jōmon pottery type that is found in Hokkaido (Kobayashi 2004: 31).

The Middle Neolithic Sony (or Yuzhno-Sakhalinsk) Culture is present in the later phases of Slavnaya 4. Radiocarbon dates from hearth charcoal and from pottery foodcrusts place this occupation in the range of 6200-5000 cal BC. Excavations produced 1386 fragments of pottery that were assigned to two phases of the Sony Culture (916 to the early phase of the Middle Neolithic and 470 to a later phase of the Middle Neolithic). The material from the later phase has walls with a more uniform thickness (approximately $6-8 \mathrm{~mm}$ ) and a more careful external surface finish.

\section{Slavnaya 5}

This Early Neolithic site is also located in the southern part of Sakhalin, approximately $350 \mathrm{~m}$ from the modern Okhotsk Sea coast. It yielded obsidian, evidence for dwellings and hearths and 30 pottery sherds (Figure 4). These come from thin-walled vessels, with mineral and organic temper. Three radiocarbon dates from charred sherd surface foodcrusts place this material in the range of $6830-6070 \mathrm{cal} \mathrm{BC}$.

\section{Chaivo 6}

This Middle Neolithic site is located in the northern part of Sakhalin, approximately $2 \mathrm{~km}$ from the coast. Radiocarbon dates on charcoal from a hearth and the floor of a pit house place the site's occupation in the range of 6000-5630 cal BC. Pottery from the site is thickwalled, porous and undecorated. Two flat-bottomed vessels could be reconstructed, with walls widening towards the mouth (Figure 5).

\section{Organic residue analyses of Early and Middle Neolithic pottery sherds}

We selected 41 vessels from the University Museum collections of Sakhalin State University and sampled either charred surface foodcrusts or absorbed residues via drilling into the sherd interior. From one sherd (sample 101), we took both surface and absorbed residues. Surface (C) Antiquity Publications Ltd, 2017 


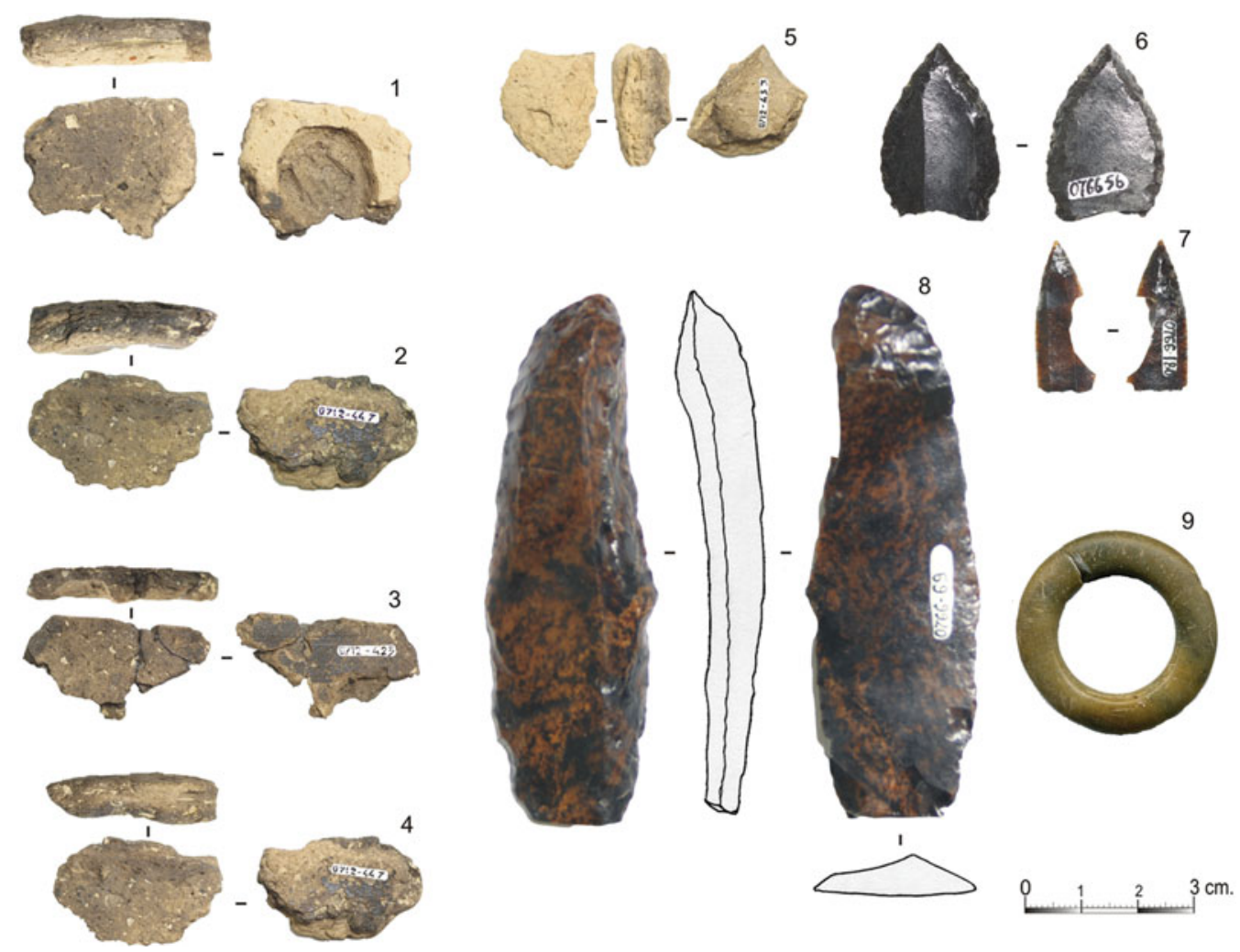

Figure 4. Early Neolithic artefacts from Slavnaya 5: pottery (1-5), stone tools (6-8) and ring (9).

foodcrusts $(\mathrm{n}=15)$ were analysed by elemental analysis-isotope ratio mass spectrometry (EA-IRMS) to determine their bulk isotope composition. Lipids were extracted from the foodcrusts and analysed by gas chromatography MS (GC-MS). The absorbed residues $(\mathrm{n}=27)$ were analysed by GC-MS and GC combustion IRMS (GC-c-IRMS). The analytical procedures are described in the online supplementary material.

\section{Bulk isotope analysis of charred surface deposits}

Bulk stable isotope values for all interior pottery foodcrusts $(\mathrm{n}=14)$ are plotted in Figure 6 . The bulk $\delta^{13} \mathrm{C}$ isotope values from Sakhalin range from -19.40 to $-25.37 \%$, and $\delta^{15} \mathrm{~N}$ values from $7.82-18.63 \%$. All foodcrust $\delta^{15} \mathrm{~N}$ values—with the exception of one Early Neolithic sample from Slavnaya 4-are greater than $9 \%$ and fall within the range expected of aquatic resources (Craig et al. 2007, 2013). Additionally, a mean $\delta^{13} \mathrm{C}$ value of $-23 \%$ o from all samples can be taken as evidence of a strong marine component in the residues (Craig et al. 2007).

While these bulk isotope values tend to suggest the processing of aquatic resources, there is notable variation in $\delta^{13} \mathrm{C}$ and $\delta^{15} \mathrm{~N}$ values across the dataset. There are a number of possible explanations for this. First, and most probably, is that the foodcrusts are derived from a variety of resources. For example, the samples with relatively high $\delta^{15} \mathrm{~N}$ values 


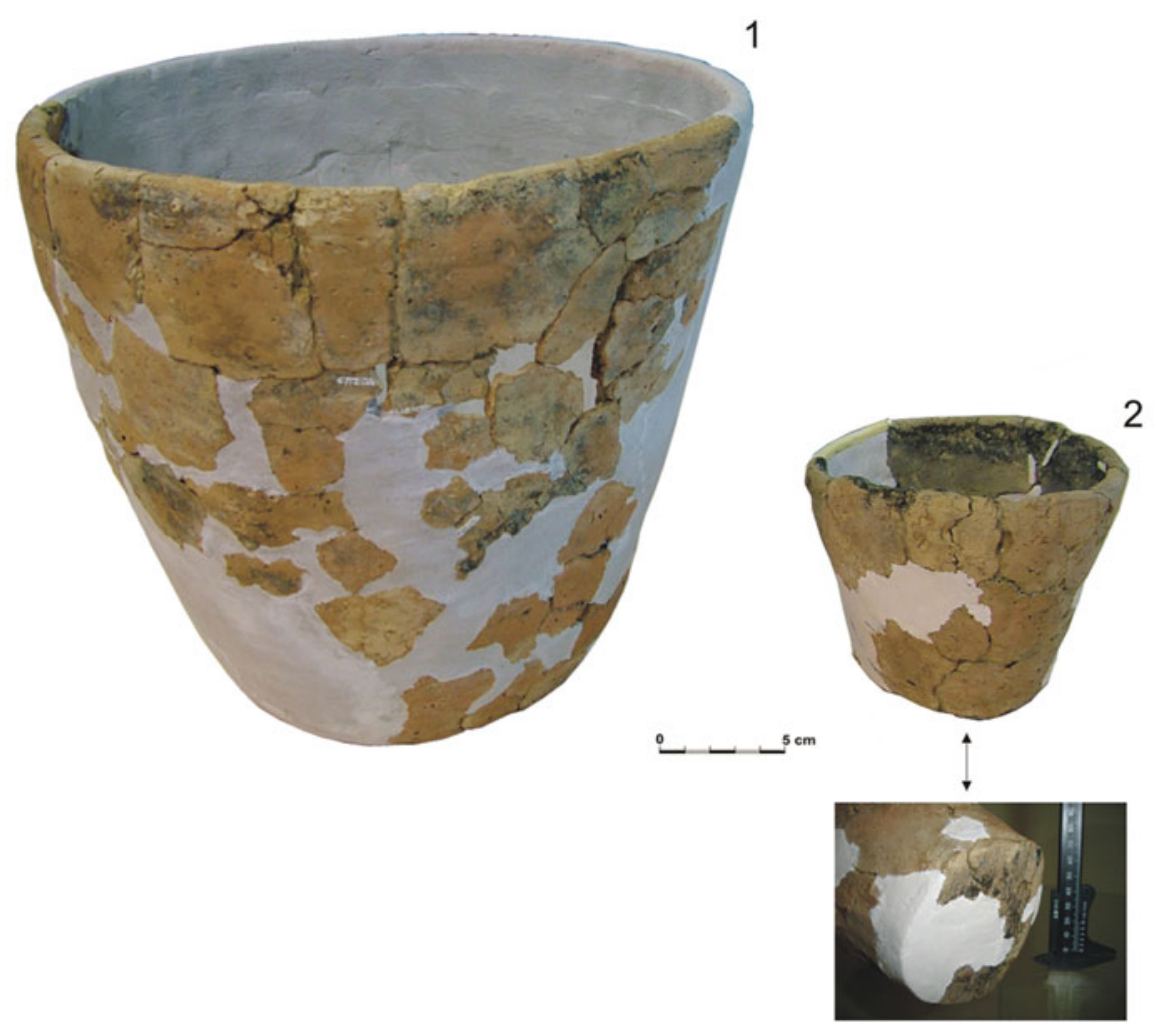

Figure 5. Middle Neolithic reconstructed pottery vessels from Chaivo 6.

$(>15 \%$ ) may derive from high trophic-level marine resources, such as mammalian marine piscivores, while those with lower values $(<15 \%$ ) may be indicative of lower trophiclevel marine resources, freshwater resources or perhaps a mixture of aquatic and terrestrial resources.

It is also possible that the variation is caused by other external factors, such as postdepositional loss of nitrogen or microbial alteration (Craig et al. 2007; Heron \& Craig 2015). Varying values may be due to differential contributions of exogenous organic matter to the sample, as bulk isotope analysis does not distinguish between endogenous and exogenous sources of organics. The relatively consistent $\mathrm{C}: \mathrm{N}$ ratios (ranging from 1.864.07) and the amount of nitrogen (ranging from 1.83-8.71\%) throughout the samples, however, make it rather unlikely that post-depositional alteration drastically influenced the data presented here. It is interesting that all of the relatively enriched values come from Early Neolithic pottery residues. There is, however, currently insufficient bulk isotope data from the Middle Neolithic to make meaningful statements concerning general patterns of change in the composition of foodcrusts between these two periods.

\section{Molecular characterisation of lipids}

The absorbed residues $(\mathrm{n}=27)$ and surface foodcrusts $(\mathrm{n}=15)$ were analysed by GCMS to obtain more specific compositional information. Of these samples, 24 absorbed (C) Antiquity Publications Ltd, 2017 
Slavnaya 4 - Early Neolithic

Slavnaya 4 - Middle Neolithic
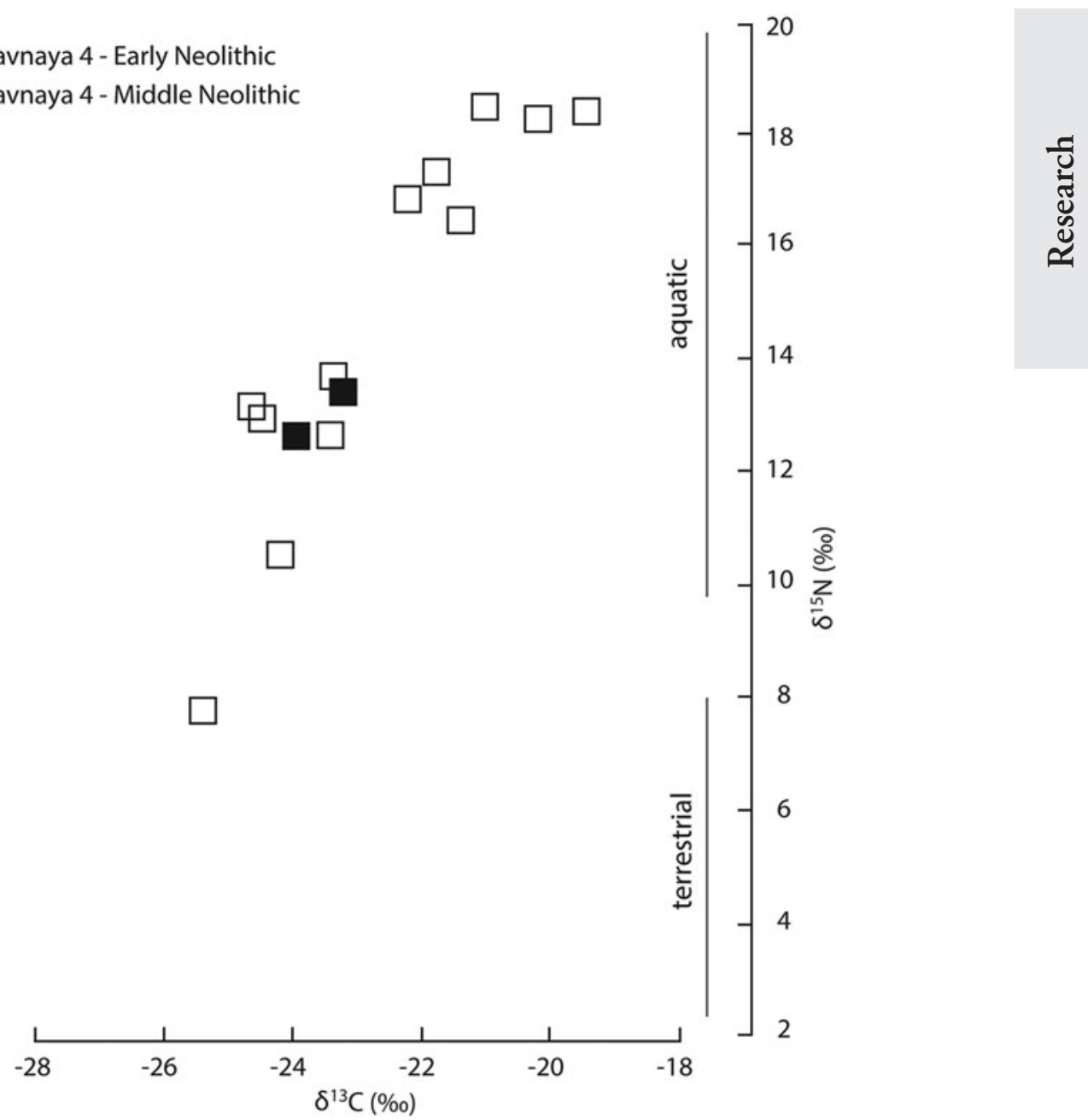

Figure 6. Bulk stable isotope values for all Sakhalin interior foodcrusts $(n=14)$.

extracts yielded interpretable lipid concentrations ( $>5 \mathrm{ug} / \mathrm{g}$ ), while all 15 of the foodcrust samples were interpretable (Table S1), although lipid preservation was relatively poor in most samples.

The general lipid profiles of the surface crusts are broadly similar in nature (Figure 7; Table S1). Saturated fatty acids range from $\mathrm{C}_{14: 0}-\mathrm{C}_{26: 0}$, while $\mathrm{C}_{16: 1}$ and $\mathrm{C}_{18: 1}$ are the only unsaturated fatty acids present. Some branched fatty acids $\left(\mathrm{C}_{15}, \mathrm{C}_{17}\right.$ and $\left.\mathrm{C}_{18}\right)$, and dicarboxylic acids $\left(\mathrm{C}_{8}-\mathrm{C}_{12}\right)$ are present in small amounts. Cholesterol in two of the samples confirms the presence of animal resources.

The general lipid profiles of absorbed residues are slightly more variable than those of the surface crusts, perhaps due to the different extraction methods used. Saturated fatty acids range from $\mathrm{C}_{12: 0}-\mathrm{C}_{30: 0}$, while monounsaturated fatty acids range from $\mathrm{C}_{16: 1-}$ $\mathrm{C}_{22: 1}$. Branched fatty acids $\left(\mathrm{C}_{15}-\mathrm{C}_{18}\right)$ and dicarboxylic acids $\left(\mathrm{C}_{7}-\mathrm{C}_{12}\right)$ are present in some 


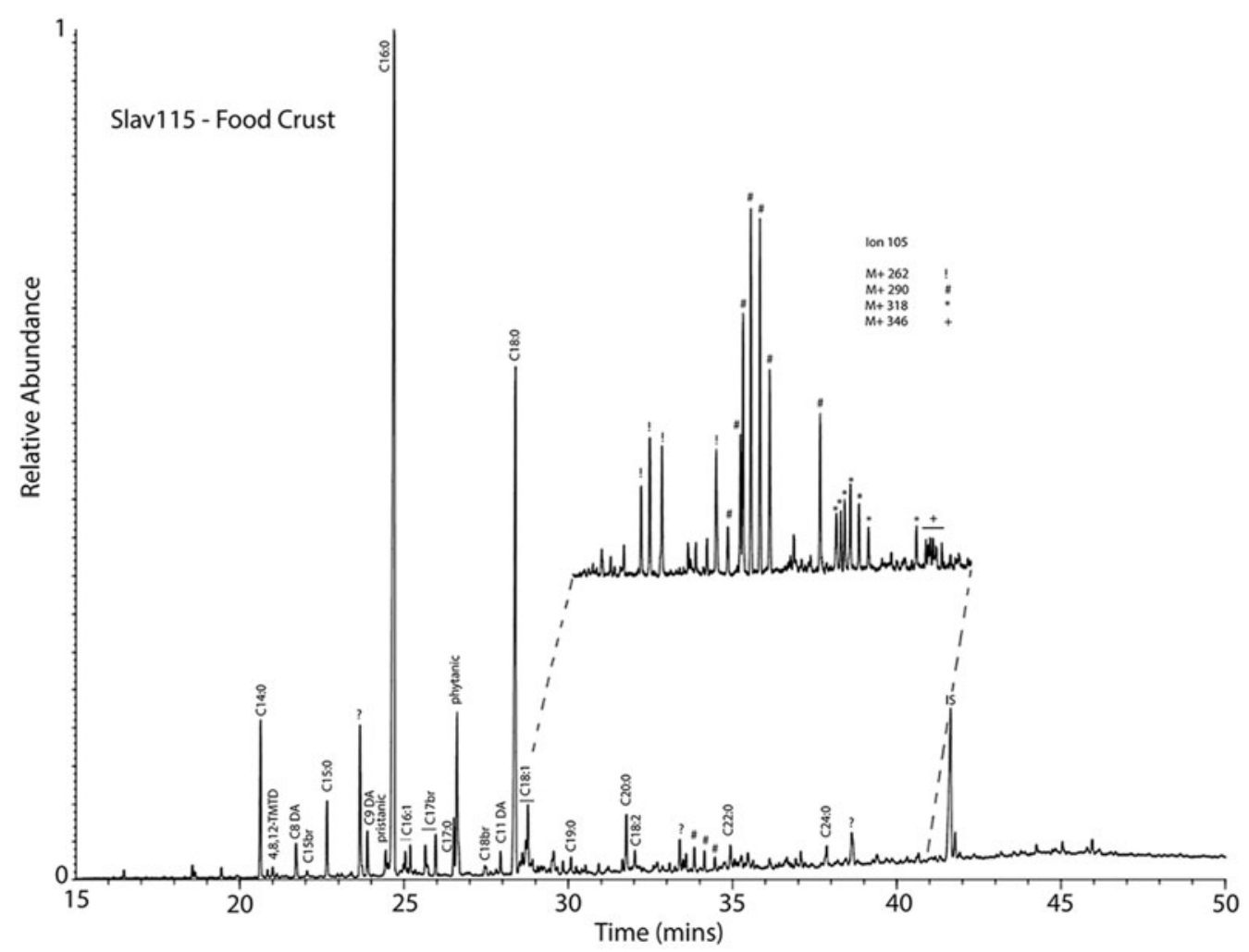

Figure 7. Example of lipid extract from sample 115, Slavnaya 4.

samples. Cholesterol is present in 14 samples, confirming the presence of animal resources. Interestingly, $\beta$-Sitosterol-a phytosterol found in plants - is present in two samples from Chaivo 6 (numbers 116 and 119). Long-chain alkanols are also present in two Early Neolithic and six Middle Neolithic samples from Slavnaya 4, which may indicate the presence of plant oils/waxes (Charters et al. 1997).

Importantly, isoprenoids (phytanic, pristanic and 4,8,12-trimethyltridecanoic acid) are present in 8 foodcrust and 18 absorbed residue samples, while $\omega$-(o-alkylphenyl) alkanoic acids (APAAs) with carbon chain lengths between 18 and 22 are present in 6 foodcrust and 5 absorbed residue samples. In combination, these are considered reliable indicators of the processing (i.e. heating) of aquatic resources in archaeological pottery (Cramp \& Evershed 2014). Isoprenoids are only found in abundance in marine and ruminant resources, while APAAs only form upon the heating of $\mathrm{C}_{18}-\mathrm{C}_{22}$ polyunsaturated fatty acids. Although particular APAAs can derive from processing certain plant and terrestrial animal sources, the presence of the whole distribution of $\mathrm{C}_{18}-\mathrm{C}_{22}$ APAAs is indicative of the processing of aquatic oils (Hansel et al. 2004; Cramp \& Evershed 2014). Compared to the foodcrust samples, the absorbed residues exhibit a relatively lower frequency of APAAs $\left(\mathrm{C}_{18}-\mathrm{C}_{22}\right)$. This could be due to the foodcrusts being exposed to higher temperatures during the use of the pottery, although taphonomy and differences in extraction or analysis conditions cannot be discounted.

(C) Antiquity Publications Ltd, 2017 


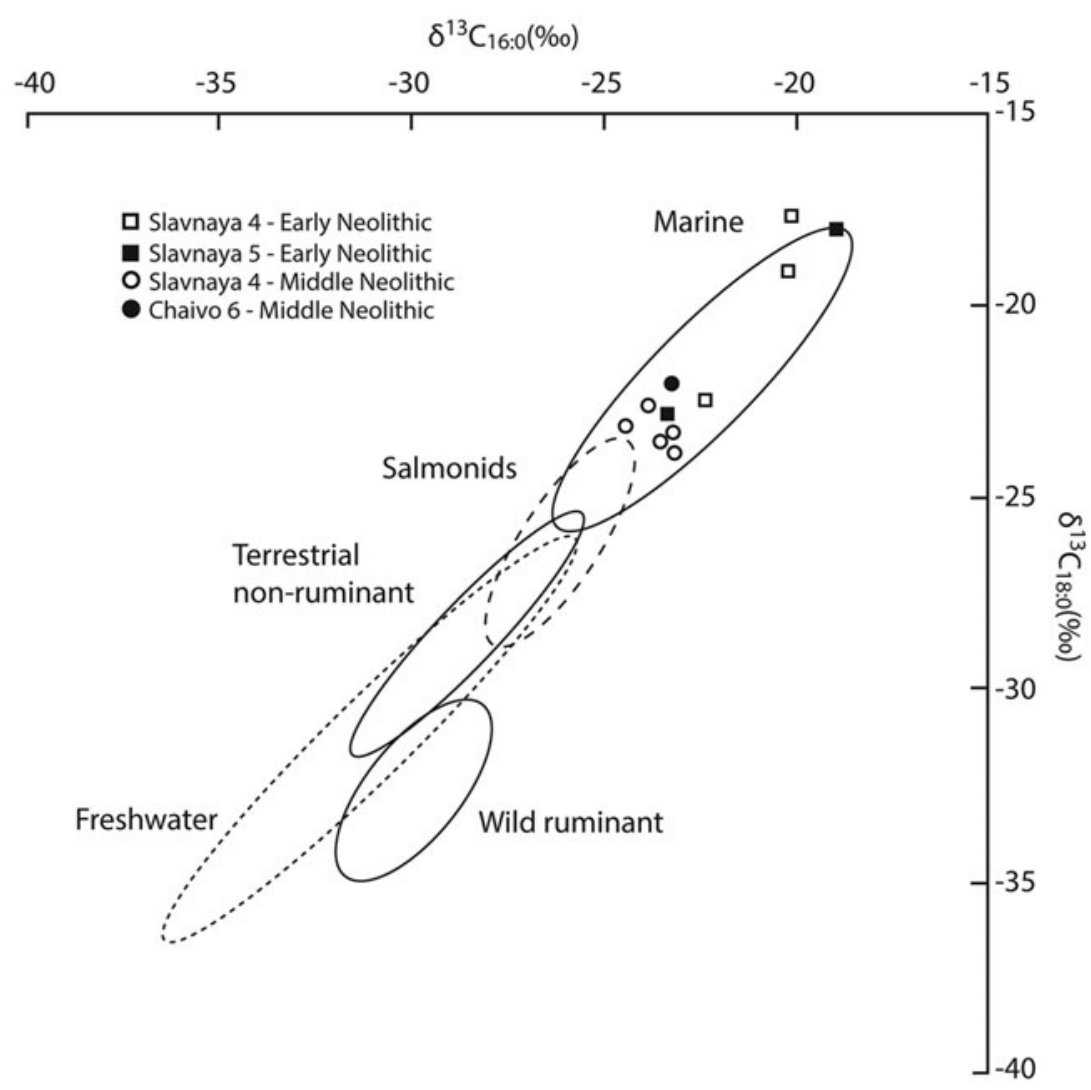

Figure 8. Plot of the $\delta^{13} C$ values of $C_{16: 0}$ and $C_{18: 0}$ fatty acids from absorbed pottery residues from Slavnaya 4, Slavnaya 5 and Chaivo $6(n=11)$. These data are compared with reference ranges for authentic reference lipids from modern tissues and archaeological bone (66.7\% confidence; see Lucquin et al. 2016 for details).

Carbon isotope analysis of fatty acids

Where lipid yields permitted, samples were analysed by GC-c-IRMS to measure the carbon isotopic composition of palmitic $\left(\mathrm{C}_{16: 0}\right)$ and stearic $\left(\mathrm{C}_{18: 0}\right)$ acids. Due to relatively low yields across all pottery and sample types, the analysis was limited to 11 absorbed residue samples (Figure 8). These included five Early and six Middle Neolithic samples. All of the samples analysed contained isoprenoids, while five of them also contained APAAs.

The GC-c-IRMS analysis provides further evidence for the processing of aquatic resources in Sakhalin pottery from both Early and Middle Neolithic sites, corroborating results from the bulk isotope and GC-MS analyses. The values for all 11 samples fall within the range expected of marine resources (Lucquin et al. 2016), with palmitic $\delta^{13} \mathrm{C}$ values ranging from -19.0 to $-24.4 \%$, and stearic $\delta^{13} \mathrm{C}$ values from -17.7 to $-23.9 \%$.

Despite a consistent marine isotope signature, there is also some notable variation within the dataset. A sub-set of Early Neolithic residues have highly ${ }^{13} \mathrm{C}$ enriched fatty acids consistent with reference fats from marine mammals and other aquatic piscivores (Lucquin et al. 2016). This suggests a preference for high trophic-level marine resources during this period. Interestingly, two samples from this group (sample numbers 87 and 103) have no 
APAAs whatsoever. The remaining samples, including both Early Neolithic and Middle Neolithic residues, however, cluster towards the lower end of the marine range.

\section{Discussion}

The results of the residue analysis strongly support the interpretation that early pottery on Sakhalin was being used to process marine aquatic resources. In all but one sample of the surface foodcrusts, the bulk isotope values fall within the range expected of aquatic resources. Additionally, aquatic biomarkers in the form of isoprenoids were found in eight samples, and APAAs $\left(\mathrm{C}_{18}-\mathrm{C}_{22}\right)$ were present in six samples. The absorbed residues tell a similar story. There is a high frequency of isoprenoids among these samples $(\mathrm{n}=18)$, and several have APAAs $\left(\mathrm{C}_{18}-\mathrm{C}_{22}\right)(\mathrm{n}=5)$. Moreover, in the samples that could be analysed with GC-c-IRMS, there was clear evidence that processing of marine resources had made a significant contribution. While the signals indicate higher trophic-level aquatic resources, however, it is difficult to determine whether this represented anadromous fish (e.g. salmon) or also included the hunting of marine mammals. Conversely, none of the samples had molecular or isotopic characteristics consistent with the processing of wild ruminant animals.

While the evidence for the processing of aquatic resources is clear, it is not possible to determine whether this involved general cooking activities or perhaps a more specialised rendering of fish oils or sea-mammal fats (Grischenko 2011: 77-78). Likewise, whether pottery was being used to prepare high-value foods for feasting at regional aggregation sites also remains uncertain (see Hayden 2009). Either way, the results presented here support the argument that pottery adoption on Sakhalin was driven by an increasing emphasis on the processing of aquatic resources - probably salmon, and possibly also marine mammals. The appearance of pottery therefore seems to be one key element in a wider Neolithic transition process that involved the cumulative replacement of the Palaeolithic terrestrial hunting economy with increased sedentism along coastal strips and the lower reaches of larger rivers-locations all offering ready access to abundant aquatic resources.

It is intriguing to note that our results from Sakhalin align well with emerging insights into the early use of pottery by other Eurasian hunter-gatherers. Focusing on some of the world's oldest pottery, Craig et al. (2013) used a similar set of methods to examine 101 pottery foodcrusts from 13 Incipient Jōmon sites across Japan, using bulk IRMS, GCMS and GC-c-IRMS. These samples date from approximately 15000-11 $800 \mathrm{cal} \mathrm{BP}$-several millennia earlier than pottery from Sakhalin-yet they also show clear evidence for the processing of aquatic organisms. Further investigation of foodcrusts and absorbed residues at one of these sites (Torihama) demonstrated that pottery had been consistently used to process aquatic resources over a 9000-year sequence, despite the major climatic and environmental changes of the Pleistocene to Holocene transition (Lucquin et al. 2016).

In the Russian Far East, Kunikita et al. (2017) examined foodcrusts from mainland sites broadly contemporaneous with the Early and Middle Neolithic on Sakhalin. They interpret carbon and nitrogen isotope ratios and C:N values as indicative of the exploitation of marine resources at the coastal sites of Boisman-2 and Vetka-2. Kuzmin's (2015) carbon and nitrogen isotope analysis of Neolithic human remains from the shell-midden site of

(C) Antiquity Publications Ltd, 2017 
Boisman-2 and the Chertovy Vorota cave site also suggests a dietary reliance on marine resources, despite archaeozoological evidence pointing to the hunting of diverse terrestrial species. Cassidy (2007) also analysed 18 Neolithic ceramic sherds from the mainland Russian Far East using GC-MS and reported evidence for aquatic species, but these date to the Terminal Neolithic-several millennia later than the earliest pottery on Sakhalin. Farther afield, hunter-gatherers in the Baltic were also using pottery for the processing of aquatic resources (Isaksson 2009; Craig et al. 2011; Cramp et al. 2014).

\section{Conclusions}

Two contrasting Neolithic trajectories can be identified in Eurasia. While the study of the classic Western Neolithic has involved the rise of farming economies in the Near East and their dispersal into north-west Europe, this paper has focused on improving current understandings of the Eastern Neolithic, which is defined by the emergence of pottery among hunter-gatherers inhabiting the remaining areas of Eurasia. Specifically, we have aimed to understand what made pottery technology attractive to hunter-gatherers living in areas adjacent to the oldest ceramic innovation centres. Our case study has focused on understanding how and why the early pottery-making traditions of northern Japan and the Lower Amur River were adopted onto Sakhalin, and the probable roles that early pottery could have played within the local Neolithic transition process.

Organic residue analysis of early pottery from different parts of Sakhalin clearly demonstrates that the vessels were being used to process aquatic resources, including high trophic-level species, most probably salmon but possibly also marine mammals. These insights lend direct support to the argument that a unique type of 'Aquatic' Neolithic was developing on Sakhalin. Beyond the adoption of pottery, the Neolithic transition process also involved the wholesale reorientation of lifeways towards the exploitation of coastal and riverine resources, encouraging growing sedentism and perhaps also population growth. It is therefore important to conclude that although the uptake of pottery on Sakhalin defines the onset of the Neolithic, its adoption appears to be closely related to a wider package of innovations and developments that were emerging at around the same time.

Looking beyond these insights from Sakhalin Island, it is tempting to speculate further that the exploitation of rich, water-edge ecosystems may have been a primary driving force behind the wider Holocene uptake of pottery among other Eurasian hunter-gatherers (Rice 1999: 10-11; Jordan \& Zvelebil 2009: 59), with the increased reliance on aquatic resources perhaps serving as the main economic foundation for the Eastern Neolithic trajectory. Properly testing this general 'aquatic' model lies beyond the scope of this article, and will require a new generation of research projects.

\section{Acknowledgements}

This research was generously supported by the UK Leverhulme Trust and is an output of the project 'Ceramics Before Farming: Prehistoric Pottery Dispersals in Northeast Asia' (code: F/00 152/AM (2011-2014); principal investigator: Peter Jordan; research fellow: Kevin Gibbs; scientific collaborator: Sven Isaksson). O.E. Craig and A. Lucquin also thank the UK Arts and Humanities Research Council for grant AH/L00691X/1, which supported 'The Innovation and Development of Pottery in East Asia' project, and A.A. Vasilevski and V.A. Grishchenko acknowledge the support of the Russian Science Foundation (project no. 14-50-00036) and the 
Ministry of Education and Science of Russia (theme 2845 in state research order no. 2014/408, 2014-2015). Sampling work was conducted during a workshop on early pottery, which was hosted by A.A. Vasilevski at the University Museum, Sakhalin State University, Yuzhno-Sakhalinsk, Russia, 7-14 March 2012. Travel funds for Japanese participants to attend this workshop were provided by the Baikal Hokkaido Archaeology Project (Social Sciences and Humanities Research Council of Canada, Major Collaborative Research Initiative (grant number 410-2011-1001); principal investigator: Andrzej Weber; co-applicant: Peter Jordan). The authors thank the two reviewers for their useful comments. All interpretations presented here remain our own, and we accept responsibility for any final errors or omissions.

\section{Supplementary material}

To view supplementary material for this article, please visit https://doi.org/10.15184/aqy. 2017.183

\section{References}

Aleksandrova, A.N. 1982. Pleistozen Sakhalina. Moskva: Nauka (in Russian).

Bronk Ramsey, C. 2009. Bayesian analysis of radiocarbon dates. Radiocarbon 51: 337-60. https://doi.org/10.1017/S0033822200033865

Cassidy, J. 2007. Patterns of subsistence change during the Final Neolithic in the Primorye region of the Russian Far East as revealed by fatty acid residue analysis, in H. Barnard \& J.W. Eerkens (ed.) Theory and practice of archaeological residue analysis (British Archaeological Reports international series 1650): 125-37. Oxford: Archaeopress.

Charters, S., R.P. Evershed, A. Quye, P.W. Blinkhorn \& V. Reeves. 1997. Simulation experiments for determining the use of ancient pottery vessels: the behaviour of epicuticular leaf wax during boiling of a leafy vegetable. Journal of Archaeological Science 24: 1-7. https://doi.org/10.1006/jasc.1995.0091

Craig, O.E., M. Forster, S.H. Andersen, E. Koch, P. Crombé, N.J. Milner, B. Stern, G.N. Bailey \& C.P. Heron. 2007. Molecular and isotopic demonstration of the processing of aquatic products in northern European prehistoric pottery. Archaeometry 49: 135-52. https://doi.org/10.1111/ j.1475-4754.2007.00292.x

Craig, O.E., V.J. Steele, A. Fischer, S. Hartz, S.H. Andersen, P. Donohoe, A. Glykou, H. Saul, D.M. Jones, E. Koch \& C. Heron. 2011. Ancient lipids reveal continuity in culinary practices across the transition to agriculture in Northern Europe. Proceedings of the National Academy of Sciences of the USA 108: 17910-15. https://doi.org/10.1073/pnas.1107202108

Craig, O.E., H. Saul, A. Lucquin, Y. Nishida, K. Taché, L. Clarke, A. Thompson, D.T. Altoft, J. Uchiyama, M. Аjimoto, K. Gibbs, S. Isaksson, C.P. Heron \& P. Jordan. 2013. Earliest evidence for the use of pottery. Nature 496: 351-54. https://doi.org/10.1038/nature12109
Cramp, L. \& R.P. Evershed. 2014. Reconstructing aquatic resource exploitation in human prehistory using lipid biomarkers and stable isotopes. Treatise on Geochemistry 14: 319-39. https://doi.org/10.1016/B978-0-08-0959757.01225-0

Cramp, L.J., R.P. Evershed, M. Lavento, P. Halinen, K. Mannermaa, M. Oinonen, J. Kettunen, M. Perola, P. Onkamo \& V. Heyd. 2014. Neolithic dairy farming at the extreme of agriculture in Northern Europe. Proceedings of the Royal Society of London B: Biological Sciences 281: article no. 20140819. https://doi.org/10.1098/rspb.2014.0819

Evershed, R.P. 2008. Organic residue analysis in archaeology: the archaeological biomarker revolution. Archaeometry 50: 895-924. https://doi.org/10.1111/j.14754754.2008.00446.x

Fukuda, M., V. Grishchenko, A. VasilevskiI, S. Onuki, T. Kumaki, D. Kunikita, K. Morisaki, H. Sato, A.V. Mozhaev, P.A. Pashentsev, A.S. Peregudov, M. Yakushige, D. Natsuki \& A. Koroku. 2015. A report of archaeological excavation at the Early Neolithic site of Slavnaya 5, Sakhalin Island, Russia. Bulletin of the Department of Archaeology, University of Tokyo 29: 121-46.

GibBs, K. \& P. Jordan. 2013. Bridging the boreal forest: Siberian archaeology and the emergence of pottery among prehistoric hunter-gatherers of Northern Eurasia. Sibirica 12: 1-38. https://doi.org/10.3167/sib.2013.120101

- 2016. A comparative perspective on the 'Western' and 'Eastern' Neolithics of Eurasia: ceramics: agriculture and sedentism. Quaternary International 419: 27-35. https://doi.org/10.1016/j.quaint.2016.01.069

Grishchenko, V.A. 2011. Rannii Neolit ostrov Sakhalin. Iuzhno-Sakhalinsk: Monografii uchenykh Sakhalinskogo gosudarstvennogo universiteta (in Russian).

(C) Antiquity Publications Ltd, 2017 
Hansel, F.A., M.S. Copley, L.A.S. Madureira \& R.P. EversheD. 2004. Thermally produced $\omega$-(o-alkylphenyl)alkanoic acids provide evidence for the processing of marine products in archaeological pottery vessels. Tetrahedron Letters 45: 2999-3002. https://doi.org/10.1016/j.tetlet.2004.01.111

Hayden, B. 2009. Foreword, in P. Jordan \& M. Zvelebil (ed.) Ceramics before farming: the dispersal of pottery among prehistoric Eurasian hunter-gatherers: 19-26. Walnut Creek (CA): Left Coast.

Heron, C. \& O.E. Craig. 2015. Aquatic resources in foodcrusts: identification and implication. Radiocarbon 57: 707-19. https://doi.org/10.2458/azu_rc.57.18454

Isaksson, S. 2009. Vessels of change: a long-term perspective on prehistoric pottery use in southern and eastern middle Sweden based on lipid residue analyses. Current Swedish Archaeology 17: 131-49.

Jordan, P. \& M. Zvelebil. 2009. Ex oriente lux: the prehistory of hunter-gatherer ceramic dispersals, in P. Jordan \& M. Zvelebil (ed.) Ceramics before farming: the dispersal of pottery among prehistoric Eurasian hunter-gatherers: 33-89. Walnut Creek (CA): Left Coast.

Jordan, P., K. Gibbs, P. Hommel, H. Piezonka, F. Silva \& J. Steele. 2016. Modelling the diffusion of pottery technologies across Afro-Eurasia: emerging insights and future research questions. Antiquity 90: 590-603. https://doi.org/10.15184/aqy.2016.68

KоваYASHI, T. 2004. Jomon reflections: forager life and culture in the prehistoric Japanese archipelago. Oxford: Oxbow.

Kunikita, D., A.N. Popov, B.V. Lazin, K. Morisaki \& H. Matsuzaki. 2017. Dating and stable isotope analysis of charred residues from Neolithic sites in the Primorye, Russian Far East. Radiocarbon 59: 565-73. https://doi.org/10.1017/RDC.2016.122

Kuzmin, Y.V. 2005. Geochronologiia i paleosreda pozdnego paleolita i neolita umerennogo poiasa Vostochnoi Azii. Vladivostok: Pacific Institute of Geography, Far Eastern Branch of the Russian Academy of Sciences (in Russian).

- 2006a. Palaeoenvironment and chronology, in S.M. Nelson, A.P. Derevianko, Y.V. Kuzmin \& R.L. Bland (ed.) Archaeology of the Russian Far East: essays in Stone Age prehistory (British Archaeological Reports international series 1540): 13-40. Oxford: Archaeopress.

- 2006b. Palaeoeconomy of the Russian Far East (Stone Age complexes), in S.M. Nelson, A.P. Derevianko, Y.V. Kuzmin \& R.L. Bland (ed.) Archaeology of the Russian Far East: essays in Stone Age prehistory (British Archaeological Reports international series 1540): 167-73. Oxford: Archaeopress.
- 2015. Reconstruction of prehistoric and medieval dietary patterns in the Russian Far East: a review of current data. Radiocarbon 57: 571-80. https://doi.org/10.2458/azu_rc.57.18426

Kuzmin, Y.V. \& M.D. Glascock. 2007. Two islands in the ocean: prehistoric obsidian exchange between Sakhalin and Hokkaido, northeast Asia. Journal of Island and Coastal Archaeology 2: 99-120. https://doi.org/10.1080/15564890701273765

Kuzmin, Y.V., A.A. VAsilevski, S.V. Gorbunov, G.S. Burr, A.J.T. Jull, L.A. Orlova \& O.A. Shubina. 2004. Chronology of prehistoric cultural complexes of Sakhalin Island (Russian Far East). Radiocarbon 46: 353-62. https://doi.org/10.1017/S0033822200039655

Lucquin, A., K. Gibbs, J. Uchiyama, H. Saul, M. Ajimoto, Y. Eley, A. Radini, C.P. Heron, S. Shoda, Y. Nishida, J. Lundy, P. Jordan, S. Isaksson \& O.E. Craig. 2016. Ancient lipids document continuity in the use of early hunter-gatherer pottery through 9,000 years of Japanese prehistory. Proceedings of the National Academy of Sciences of the USA 113: 3991-96. https://doi.org/10.1073/pnas.1522908113

Mikishin, Y. \& I.G. Gvozdeva. 1996. The natural evolution in the south-eastern part of Sakhalin Island in the Holocene. Vladivostok: Far East State University Press (in Russian).

Popov, A.N., A.V. Tabarev \& Y.A. Mikishin. 2014. Neolithization and ancient landscapes in southern Primorye, Russian Far East. Journal of World Prehistory 27: 247-61. https://doi.org/10.1007/s10963-014-9073-1

Reimer, P.J., E. Bard, A. Bayliss, J.W. Beck, P.G. Blackwell, C. Bronk Ramsey, C.E. Buck, H. Cheng, R.L. Edwards, M. Friedrich, P.M. Grootes, T.P. Guilderson, H. Haflidason, I. Hajdas, C. Hatté, T.J. Heaton, D.L. Hoffmann, A.G. Hogg, K.A. Hughen, K.F. Kaiser, B. Kromer, S.W. Manning, M. Niu, R.W. Reimer, D.A. Richards, E.M. ScotT, J.R. Southon, R.A. Staff, C.S.M. Turney \& J. van der Plicht. 2013. IntCal13 and Marine13 radiocarbon age calibration curves $0-50,000$ years cal BP. Radiocarbon 55: 1869-87. https://doi.org/10.2458/azu_js_rc.55.16947

RiCE, P. 1999. On the origins of pottery. Journal of Archaeological Method and Theory 6: 1-54. https://doi.org/10.1023/A:1022924709609

Rudaya, N., A. Vasilevski, V. Grishchenko \& A. Mozhaev. 2013. Environmental conditions of the Late Paleolithic and Early Neolithic sites in southern Sakhalin. Archaeology, Ethnology and Anthropology of Eurasia 41: 73-82. https://doi.org/10.1016/j.aeae.2013.11.007 
Uchiyama, J., J.C. Gillam, L.A. Hosoya, K. LindSTRÖM \& P. JoRDAN. 2014. Investigating Neolithization of cultural landscapes in East Asia: the NEOMAP Project. Journal of World Prehistory 27: 197-223. https://doi.org/10.1007/s10963-014-9079-8

VAsileVKsi, A.A. 1994. Work of the Lutogskaya Palaeolithic expedition in 1994: archaeological discoveries of 1994. Moscow: IARAS (in Russian).

- 1998. Adaptive strategy, man's activity and landscape: Sakhalin Island in Holocene period, in Rekihaku international symposium: terrestrial environmental changes and natural disasters during the last 10000 years: 358-61. Sakura: National Museum of Japanese History.

- 2003. Periodization and classification of the Upper Paleolithic of Sakhalin and Hokkaido in the light of research conducted at the Ogonki 5 site.

Archaeology, Ethnology and Anthropology of Eurasia 4(3): 51-69.

- 2008. Kamennyi vek ostrova Sakhalin.

Yuzhno-Sakhalinsk: Sakhalinskoe knizhnoe izdatel'stvo (in Russian).

VAsilevski, A.A. \& O.A. Shubina. 2002. Neolithic of Sakhalin and the Kuril Islands. Bulletin of the Sakhalin Museum 9: 196-231 (in Russian).
- 2006. Neolithic of the Sakhalin and southern Kurile Islands, in S.M. Nelson, A.P. Derevianko, Y.V. Kuzmin \& R.L. Bland (ed.) Archaeology of the Russian Far East: essays in Stone Age prehistory

(British Archaeological Reports international series 1540): 151-66. Oxford: Archaeopress.

Vasilevski, A.A., V.A. Grischenko \& L.A. Orlova. 2010. Periods, boundaries, and contact zones in the Far Eastern insular world of the Neolithic (based on the radiocarbon chronology of sites on the Sakhalin and Kuril Islands). Archaeology, Ethnology and Anthropology of Eurasia 38: 10-25.

Vostretsov, Y.E. (ed.). 1998. Pervye rybolovy $v$ zalive Petra Velikogo: Drevni chelovek v bukhte Boismana. Vladivostok: Dalpress (in Russian).

ZhushснікноvsкаYа, I.S. 2009. Pottery making in prehistoric cultures of the Russian Far East, in P. Jordan \& M. Zvelebil (ed.) Ceramics before farming: the dispersal of pottery among prehistoric Eurasian hunter-gatherers: 121-47. Walnut Creek (CA): Left Coast.

Zhushchikhovskaya, I.S. \& O.A. Shubina. 2006. Pottery making and the culture-history of Neolithic Sakhalin, in D.E. Dumond \& R.L. Bland (ed.) Archaeology in northeast Asia: on the pathway to Bering Strait (University of Oregon Anthropological Papers 65): 91-128. Eugene: Museum of Natural and Cultural History and Department of Anthropology, University of Oregon.

Received: 7 July 2016; Accepted: 22 November 2016; Revised: 6 June 2017

(C) Antiquity Publications Ltd, 2017 